\title{
Integration and Development of Archives Information Resources in the Internet Age
}

\author{
Yu Ting \\ Wuhan City Polytechnic, China,430064
}

\begin{abstract}
Keywords: Internet; college archives information resources; utilization development
\end{abstract}
\begin{abstract}
Under the background of the Internet as the main feature, archive informationization has become an important direction for the development of college archives. With the introduction and application of new technologies, new ideas and new methods in the archives work of colleges and universities, the archives work has undergone different degrees of change in the work procedures, links and contents.
\end{abstract}

\section{Introduction}

"Internet Archives" is a modern concept of taking advantage of the trend. Yang Dongquan, director of the National Archives Bureau, pointed out at the National Archives (Consulate) meeting held on December 23, 2014 that it is necessary to "plug the traditional archives into the modern wings of the Internet." Just as the Internet emphasizes the deep meaning after the plus, the network strength is a proposition of the times, and the archives cause in the network era is advancing with the times. Under the new situation, the development and utilization of archives information resources in colleges and universities should "clear goals, form characteristics, and take advantage of the trend", that is, clarify the service direction of college archives, enrich archive resources, enhance the systematic nature of archives, and use information technology to improve archive services. s efficiency. Take all effective measures to promote the archives service in an orderly manner to meet the needs of college education reform and development[1].

\section{The significance of the development and utilization of archives information resources in colleges and universities under the new situation}

With the full implementation of the national strategy of rejuvenating the country through science and education, China's higher education has developed rapidly. Improving the quality of education and teaching has become the top priority of the development of colleges and universities. While continuously improving the level of teaching and research in universities, we must speed up the development and utilization of archives. Steps, smooth access to various channels of archives, realize the sharing of archives information resources, and make the archives work play a practical role in the teaching, research and management of colleges and universities. Its important significance is embodied in the following aspects: providing services for decision makers, teaching Research services. The archives information resources of colleges and universities are authoritative, authentic and comprehensive. They are an important source of information for schools. When school leaders face a major problem, they need to refer to these archive resources as the basis for decision-making; It records the valuable factual data and scientific research results of teachers and students in teaching and research activities. These valuable data reflect the comprehensive strength and education level of the school from the side. Serve the teachers and students of the school and the community. The ultimate goal of the collection and management of archival materials is to make extensive use of these resources to meet the needs of teachers and students. If you can make good use of the archives' own advantages to prepare the development process of the school, students will carry out fine traditional education and patriotism education and quality education. In addition, according to their actual conditions, the Document Service Utilization Center can be established to publicize the school's rules and regulations, relevant documents, development plans, financial 
reports, departmental settings, and leadership divisions to the teachers and students of the school, increase the transparency of the school, and enhance the school. The democratization of the construction, and the university archives to create a fast platform for faculty, students and the community to provide various services[2].

\section{Points combined with the overall plan to explore a new method of strong energy gathering}

Network strength is not only the requirement for the comprehensive deepening reform of college archives, but also the inevitable requirement for the development of college archives. How to coordinate the overall situation, highlight key points and grasp the joint is the key.

\subsection{Relying on the overall situation of the network to strengthen the country, do a good job in the overall planning of the network}

The network must break through the traditional college file service model and advance in the network power strategy to absorb more nutrition from the Internet action plan. Research and develop a strategy for the integration of archives network security and information services, relying on network powers to refine the construction of archives information, and promote the development goals, construction priorities, integration models and countermeasures of archive network services. Strengthen the integration design of network services and traditional services, implement the public and private, global and regional construction plans for the detailed archives service network, and organically integrate the infiltration and extension characteristics of information networks with traditional services. Establish a file network information sharing mechanism, expand the archive network to build a win-win channel, build a three-dimensional archive information network security protection system, strengthen the supervision of archival network security and information major projects, and promote the scientific development of archive network construction.Internet file network management mode as shown below.

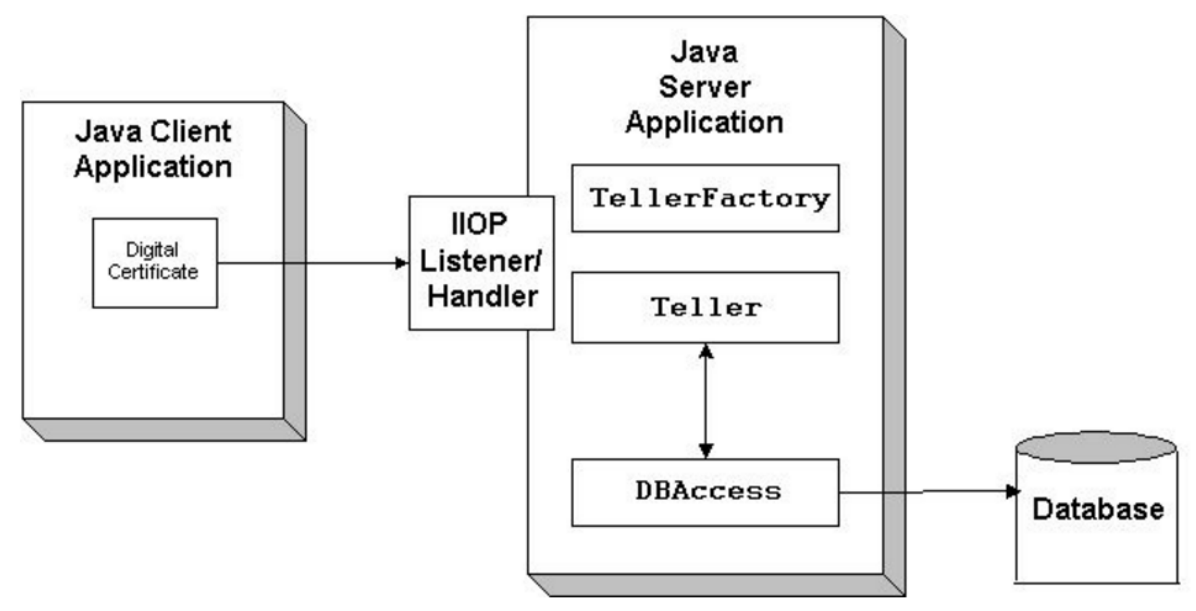

Fig.1 Internet file network management mode

\subsection{Do a good job in building information strength and enhance the viability of the network}

The network is the foundation, and the power of information is the main reason for exploring the network service capabilities of colleges and universities. In the reform and development, we attach importance to the information power, and according to the principle of information power priority, scientifically design the overall strength structure of the archives, and reasonably determine the talent needs of different types of colleges such as network application, information service and information security. Strengthen the systematic construction of information power in colleges and universities, from the internal "addition and subtraction method", adopt the traditional service talent transformation, professional strength expansion, functional task adjustment, etc., as soon as possible to form an information power system to meet the needs of college information services. Continue to pay attention to the improvement of the information power of colleges and universities, organize the 
use of archives and information forces to jointly use simulation exercises and strengthen training. In the cyberspace confrontation environment, "smash" and exercise information power[3].

\subsection{Explore the network strong energy gathering method according to the one-stop service requirements}

The strong network of colleges and universities is focused on networking. Establishing a service-oriented network application concept, abandoning the network construction of colleges and universities is only responsible for the "pipeline" concept of the localism, and actively combining the network construction with the construction of university archives library, the construction of college archives resource system and the construction of college archives security system. The university's information-as-a-service, platform-as-a-service and software-as-a-service file utilization service systems are built to enhance the adhesion of university archives networks. Improve the comprehensive network application level of colleges and universities, change the single-network application to multi-network use, organically combine network application with information application, technology application and talent application to solve the problem of "two skins" for network application and information service. Exploring the network application effect of one-stop service, aiming at users' full utilization and sharing of information, changing the information flow of a single archive to the information flow of multiple archives, and putting the information activities and technical activities of the university into the same structure Organizations, using the aggregation of college archives information to trigger the surge of college file services[4]. Internet file management system as shown below.

\section{Ultra-S 5 ASST Indexed Search}

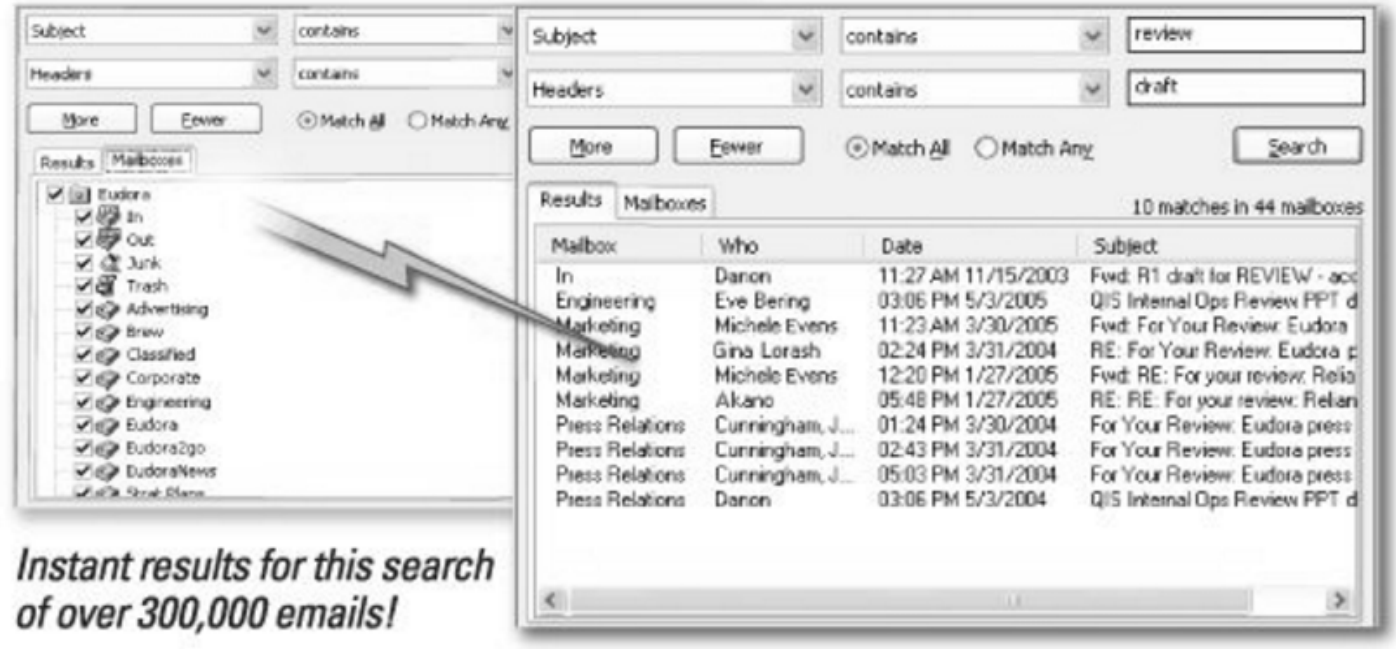

Fig.2 Internet file management system

\section{Relaxing the vision of innovative services to optimize service results}

In order to effectively alleviate the contradiction between supply and demand of colleges and universities, the archives department of colleges and universities should establish the concept of big service and develop towards openness, individuality, diversification, network and intelligence.

\subsection{Broaden your horizons and expand your service target}

University archives are rich in content in teaching, scientific research, administrative management and other activities. They record the historical changes of colleges and universities, the growth experience of students and the carrier of innovative development of teaching and research, including paper, photos, audio and video. , CD, disk and other forms. These resources not only play a role in staff planning and decision-making for the school's planning and development, but also play a role as a basis and a voucher for the student's academic review. They serve as a reference and 
reference for teachers' teaching and research, and also play an important role for off-campus groups, organizations and individuals. Radiation and education. Therefore, while serving the fundamentals of teachers, students and alumni of the school, college archives must be brave enough to make breakthroughs, proactively contact the society, serve the public, and expand the service field from the school to the region, the industry and the whole society.

\subsection{Using technology, innovative service methods}

The development of information science provides us with advanced technologies such as mobile internet, cloud computing and big data. The use of these technologies will help university archives departments to implement multi-dimensional information service methods such as knowledge mining services, statistical analysis services, online interactive services, and mobile platform services. Provide knowledge mining and statistical analysis services to users through technologies such as cloud computing and data mining. With the help of the Internet and Internet of Things technologies, college archives departments can build user interaction platforms, enhance communication between archives departments and users, timely understand user utilization needs, judge user behavior habits, and speculate user behavior trajectories, so as to be more personalized. Serve users and retain users. With the help of mobile Internet technology, college archives departments can launch WeChat platform services, popularize archive knowledge, provide online consultation, promote collection information, and disseminate archive culture.

\section{Summary}

Whether the work of college archives services is effective, the quality of service is the standard; whether the service has quality and meets the needs of users is the ruler. In order to improve the service level and optimize the service effect, college archives departments must focus on user needs and customer satisfaction as the scale.

\section{Acknowledgement}

The key subject of Wuhan City Vocational College: research on the Construction of Scientific Research team in higher Vocational Colleges

\section{References}

[1] Claire Warwick, Melissa Terras, Isabel Galina, Paul Huntington, Nikoleta Pappa. Library and information resources and users of digital resources in the humanities[J]. Program: electronic library and information systems,2008,42(1).

[2] Liu Jiazhen, Yang Daoling. Status of the preservation of digital resources in China: results of a survey[J]. Program: electronic library and information systems,2007,41(1).

[3] Japanese History Studies and the Internet Resources[J]. Computer \&amp; Education,2005,18(0).

[4] Goran Pavelin. Efficiency of PR communication in establishing links between archives and students: case study of the State Archives in Zadar[J]. Libellarium: journal for the research of writing, books, and cultural heritage institutions,2013,5(2). 